\title{
AVALIAÇÃO NUTRICIONAL DE CEREAIS EXTRUSADOS PARA CÃES ${ }^{1}$
}

\author{
Nutritional evaluation of extruded cereals for dogs
}

\author{
Anderson Duarte ${ }^{2}$, Flávia Maria de Oliveira Borges Saad ${ }^{3}$, James Jim Corbim \\ José Walter da Silva Júnior ${ }^{5}$, Derly Andrieli Ramos Pereira, \\ Elias Tadeu Fialho ${ }^{3}$, Paulo Borges Rodrigues ${ }^{3}$
}

\begin{abstract}
RESUMO
Avaliou-se a digestibilidade de matérias-primas de origem vegetal (milho, milho degerminado, sorgo e quirera de arroz) submetidas ao processamento de extrusão. Foram selecionados oito cães da raça FOXHOUND AMERICANO, machos, com idade de três anos e peso médio de $32,0 \mathrm{Kg} \pm 2,4 \mathrm{Kg}$. Cada tratamento, de um total de quatro, foi oferecido a dois cães, durante quatro períodos, em um total de oito cães por tratamento. Nas amostras de alimentos e fezes foram realizadas análises de matéria seca, fibra bruta, gordura em hidrólise ácida, proteína bruta, matéria mineral, extrativo não nitrogenado e energia bruta. O delineamento foi em duplo quadrado latino (quatro tratamentos, quatro períodos e oito cães), totalizando 32 unidades experimentais. As médias dos coeficientes de digestibilidade dos vários nutrientes dos tratamentos experimentais foram comparados pelo teste SNK com 5\% de probabilidade. Os resultados para o milho degerminado foram: coeficiente de digestibilidade aparente da matéria seca $(\mathrm{DAMS})=67,82 \%$; da matéria orgânica $(\mathrm{DAMO})=71,60 \%$; da proteína bruta $(\mathrm{DAPB})=69,95 \%$; da gordura em hidrólise ácida $(\mathrm{DAGHA})=79,52 \%$. Estes resultados mostram que o milho degerminado é um ingrediente de baixo valor nutricional quando comparado com o milho integral (DAMS, 82,28); (DAMO, 87,19); (DAPB, 73,28); (DAGHA, 88,72), sorgo (DAMS, 86,43); (DAMO, 87,48); (DAPB, 71,01); (DAGHA, 86,88) e quirera de arroz (DAMS, 95,00); (DAMO, 95,62); (DAPB, 82,57); (DAGHA, 92,66). Não ocorreram diferenças (P>0,05) entre o milho integral e o sorgo. A quirera de arroz apresentou maior coeficiente de digestibilidade dos nutrientes dentre os ingredientes avaliados. Os resultados encontrados neste trabalho demonstram que diferentes fontes de carboidratos como milho e sorgo podem ser utilizados de forma equivalente, na nutrição de cães. O milho degerminado deve ser utilizado com cautela devido ao seu menor perfil nutricional dentre os cereais avaliados, devendo ser melhor avaliado para produtos com objetivo de redução calórica.
\end{abstract}

Termos para indexação: Digestibilidade, milho, milho degerminado, sorgo, arroz integral.

\begin{abstract}
Digestibility of extruded raw materials of vegetal origin (corn, degerminated corn, sorghum, and brewer's rice) was evaluated in this experiment. Eight similar male dogs from AMERICAN FOXHOUND breed had been selected, at the ages of three years old and average weight of $32,0 \mathrm{~kg} \pm 2,4 \mathrm{~kg}$. Each treatment, from a total of four, was offered to two dogs, during four periods, in a total of eight dogs per treatment. Dry matter, crude fiber, acid-hydrolyzed fat, crude protein, ash, non-nitrogen extract and gross energy were analyzed in the samples of feed and excrements (feces). It was used a double Latin square design (four treatments, four periods and eight dogs) totalizing 32 experimental units, and the averages of digestibility coefficient of some nutrients, SNK procedures was used to identify differences among treatments means. Results for degerminated corn was: dry matter apparent digestibility coefficient (DMADC) = $67,82 \%$; organic matter $(\mathrm{OMADC})=71,60 \%$; crude protein $(\mathrm{CPADC})=69,95 \%$; acid-hydrolyzed fat $(\mathrm{AHFADC})=79,52 \%$. These results show that the degerminated corn has a low nutritional value when compared to whole grain corn (DMADC, 82,28); (OMADC, 87,19); (CPADC, 73,28); (AHFADC, 88,72), sorghum (DMADC, 86,43); (OMADC, 87,48); (CPADC, 71,01); (AHFADC, 86,88) and brewer's rice (DMADC, 95,00); (OMADC, 95,62); (CPADC, 82,57); (AHFADC, 92,66). There were no significant difference (P>0,05) between whole grain corn and sorghum. Brewer's rice showed the highest digestibility coefficient of the nutrients amongst the evaluated ingredients. The results found in this experiment demonstrate that different sources of carbohydrates, such as corn and sorghum may be equivalent used in the nutrition of dogs. Degerminated corn should be used with caution due to its lowest nutritional profile amongst the evaluated cereals, also should be better evaluated for products with the objective to the energy reduction.
\end{abstract}

Index terms: Digestibility, corn, degerminated corn, sorghum, brewer's rice.

(Recebido para publicação em 2 de junho de 2005 e aprovado em 7 de dezembro de 2005)

\section{INTRODUÇÃO}

A história evolutiva dos cães comprova que, há muito tempo, eles possuem uma dieta onívora, porém rica em proteína e gordura de origem animal (TARDIN, 2002), entretanto a tecnologia de extrusão e também os custos fizeram com que o carboidrato se tornasse um importante componente das rações comerciais.

\footnotetext{
${ }_{1}^{1}$ Parte da dissertação apresentada ao Departamento de Zootecnia da Universidade Federal de Lavras/UFLA - Cx. P. 3037 - 37200-000 - Lavras, MG.

${ }^{2}$ Mestre em Zootecnia pela Universidade Federal de Lavras/UFLA - Rod. Fernão Dias, Km 699 - Distrito Industrial - Cx. P. 70 - $37410-000$ - Três Coracõos, MG-anderson@totalalimentos.com.br

${ }_{3}^{3}$ Professor do Departamento de Zootecnia da Universidade Federal de Lavras/UFLA - Cx. P. 3037 - 37200-000 - Lavras, MG.

${ }^{4}$ Professor Emérito da Universidade de Illinois - USA.

${ }^{5}$ Aluno do curso de Doutorado em Zootecnia na Universidade Federal de Lavras/UFLA - Cx. P. 3037 - 37200-000 - Lavras, MG.

${ }^{6}$ Engenheiro Químico/Alimentos.
} 
Entre os cereais mais comumente utilizados em alimentos processados para cães encontram-se o milho e seus derivados, o arroz e seus derivados e, em menor proporção, o sorgo. O processamento do grão de milho pode alterar o seu valor nutritivo pela moagem, gelatinização, floculação e laminação (GONÇALVES \& BORGES, 1997). O milho degerminado tem grande aceitação em cervejarias e indústrias fabricantes de salgadinhos e cereais matinais, podendo se apresentar como um ingrediente opcional na alimentação animal. $\mathrm{O}$ sorgo é indicado como um bom substituto do milho na produção agrícola e na alimentação animal, mas aspectos culturais que afetam o comportamento dos agentes do agronegócio do Brasil dificultam esta substituição e geram problemas de mercado para o produto (DUARTE, 2000).

O maior uso de grãos de sorgo no Brasil está na avicultura e suinocultura. Bovinos, eqüinos e pequenos animais são também consumidores, mas em menor proporção. Praticamente não há consumo de sorgo na alimentação humana (RIBAS, 2000). Segundo Borges (2002), a digestão do amido do sorgo ocorre de forma mais lenta que do amido do milho e o processo de extrusão nas rações de cães e gatos pode melhorar a digestibilidade da proteína do sorgo (FAPOJUWO et al., 1987).

Muito utilizada na alimentação animal, a quirera de arroz é bastante semelhante ao arroz em relação à sua composição química. Silva Júnior (2004) encontrou valores de digestibilidade da matéria seca de $87,43 \%$ em uma dieta para cães contendo $60 \%$ de quirera de arroz, superiores $(\mathrm{P}<0,05)$ àqueles encontrados para dietas com $60 \%$ de sorgo integral $(81,11 \%)$ e com $60 \%$ de milho integral $(82,94 \%)$.

Segundo Twomey et al. (2002), o processo de extrusão envolvido na produção de alimentos para cães e gatos é adequado para gelatinizar o amido e aumentar sua digestibilidade.

Para cães, o grau de digestão do carboidrato dependerá do processamento que a dieta foi submetida (BORGES \& FERREIRA, 2004).

A capacidade de inchamento dos cereais possui uma correlação alta e positiva dentro de todas as qualidades organolépticas da ração, como textura, sabor e aceitabilidade. Por outro lado, o conteúdo de amilose guarda uma correlação negativa com todas as características organolépticas (FAO, 2002).

O processo de cozimento por extrusão tem sido usado em alimentos para cães e gatos há mais de 50 anos. O primeiro alimento extrusado foi desenvolvido pela
Ralston Purina Company, em 1954 (CORBIN, 2003). Extrusoras são equipamentos complexos que podem trazer mudanças significativas para ingredientes alimentícios sob condições tipicamente empregadas no processo de cozimento. Segundo Smith (1975), citado por Carvalho (2002), extrusão é o processo de cozimento realizado pela combinação de umidade, pressão, calor e atrito mecânico no interior de um tubo.

Além de serem necessários ao processo de extrusão para moldar o alimento, os cereais são fontes mais econômicas de nutrientes (TARDIN, 2002). Assim, o amido, hoje representado pelos cereais, compõe a maior parte da formulação de alimentos completos para cães (LEWIS et al., 1994).

O mercado de alimentos para estes animais já movimenta hoje cerca de dois bilhões de reais no Brasil. Segundo a Associação Nacional dos Fabricantes de Alimentos para Animais (ANFAL, 2005), a produção de alimento industrializado para cães e gatos passou de 220 mil toneladas no ano de 1994 para 1.428 .000 toneladas de ração em 2004; há uma estimativa, para 2005, de 1.502.000 toneladas, e o setor é responsável por 12.000 empregos diretos somente na indústria.

Diante desse cenário nacional, a indústria é carente de informações referentes aos ingredientes disponíveis no País. A maioria das pesquisas realizadas para avaliação nutricional de ingredientes de origem vegetal é oriunda de outros países, sendo que muitas delas de caráter confidencial das empresas que atuam no ramo, sem considerar que determinadas situações são específicas de cada continente.

Diante do exposto, objetivou-se com este trabalho avaliar o valor nutricional de quatro ingredientes de origem vegetal (milho integral moído, quirera de arroz, sorgo integral moído e milho degerminado), submetidos à mesma condição de processamento de extrusão e oferecidos puros, por técnica de alimentação forçada, para cães adultos.

\section{MATERIAL E MÉTODOS}

Foram utilizadas as instalações da estação experimental da empresa Total Alimentos S/A, na cidade de Três Corações. Cada animal foi acondicionado em canil individual com área média de $3,5 \mathrm{~m}^{2}$, sendo o piso do canil de cimento liso, sem solário, para que fosse possível a coleta total de fezes. Os bebedouros utilizados foram do tipo "nipple", fixados na parede do fundo do canil a uma altura média de $50 \mathrm{~cm}$. Utilizaram-se cães da raça Foxhound Americano, machos, inteiros, com idade de três

Ciênc. agrotec., Lavras, v. 30, n. 6, p. 1177-1183, nov./dez., 2006 
anos (+ seis meses). Foram selecionados 8 animais de peso de 35 quilos ( $\pm 2,4$ quilos), distribuído em quatro tratamentos. As dietas (tratamentos) foram extrusadas, em condições idênticas, pela empresa Total Alimentos S.A. e oferecidas aos animais da estação de pesquisa da empresa. Quatro dietas (tratamentos) foram oferecidas aos animais, compostas unicamente do cereal a ser testado (milho integral, milho degerminado, sorgo integral e quirera de arroz).

Todos os cereais avaliados entraram em uma proporção de $99,85 \%$ na dieta e, foram complementados com $0,15 \%$ de premix mineral vitamínico, proporcionando as necessidades mínimas de microelementos minerais e vitamínicos (AAFCO, 1994).

Para fornecimento das dietas foi desenvolvido um sistema de bombeamento, tendo acoplado a sua saída, um tubo flexível, de material atóxico, com diâmetro de 3/4 de polegadas e comprimento suficiente para ser introduzido até o estomago do cão.

O experimento teve duração de 20 dias, divididos em quatro períodos de cinco dias, período em que todos os oitos cães receberam as quatro dietas de maneira alternada. Nos três primeiros dias de cada período experimental procedeu-se à fase de adaptação, em que os animais foram entubados e receberam 500 gramas de cada dieta adicionados em 500 gramas de água aquecida a $36^{\circ} \mathrm{C}$.

A colheita de fezes foi realizada para cálculo dos coeficientes de digestibilidade aparente da matéria seca (DAMS), digestibilidade aparente da matéria mineral (DAMM), digestibilidade aparente da matéria orgânica (DAMO), digestibilidade aparente da proteína bruta (DAPB), digestibilidade aparente da gordura por hidrólise ácida (DAGHA), digestibilidade aparente da fibra bruta (DAFB), digestibilidade aparente do extrativo não nitrogenado (DAENN) e digestibilidade aparente da energia bruta (DAEB), alem dos valores de energia digestível aparente (EDA). Colheram-se todas as fezes de cada animal num período de dois dias.

As análises de energia bruta foram realizadas no Laboratório de Pesquisa Animal do Departamento de Zootecnia da UFLA, MG, e as demais análises foram realizadas no laboratório interno da empresa Total Alimentos S.A, em Três Corações, MG. As análises bromatológicas foram realizadas segundo metodologia da AOAC (1995) e, análises de energia bruta segundo Silva \& Queiroz (2002) e energia metabolizável estimada segundo Instrução Normativa 09 do Brasil (2003).

O delineamento utilizado foi o quadrado latino duplo (4 períodos e 4 dietas, com 2 repetições por período, totalizando oito cães). Após a seleção, os tratamentos foram sorteados por método totalmente aleatório aos cães, de modo a existirem dois cães para cada tratamento no mesmo período, assim, cada tratamento teve oito repetições.

As médias dos coeficientes de digestibilidade dos vários princípios nutritivos das dietas experimentais foram comparadas pelo teste SNK (nível de significância 5\%), utilizando-se o programa estatístico "SISVAR for Windows" (FERREIRA, 2000).

\section{RESULTADOS E DISCUSSÃO}

Na Tabela 1, encontram-se os valores médios dos coeficientes da digestibilidade aparente da matéria seca (DAMS), da matéria mineral (DAMM) e da matéria orgânica (DAMO), expressos em porcentagem, dos quatro tratamentos em estudo. As DAMS do milho e do sorgo não apresentaram diferença $(\mathrm{P}>0,05)$, enquanto a quirera de arroz e o milho degerminado diferiram entre si $(\mathrm{P}<0,05)$ e das demais. $\mathrm{O}$ milho degerminado apresentou a menor DAMS.

TABELA 1 - Coeficientes $(\%)$ de digestibilidade aparente da matéria seca (DAMS), da matéria mineral (DAMM) e da matéria orgânica (DAMO), do milho integral, milho degerminado, sorgo integral e quirera de arroz em cães.

\begin{tabular}{lccc}
\hline \multicolumn{1}{c}{ Cereal } & $\begin{array}{c}\text { DAMS }(\%) \\
\left.\text { Média }^{\mathbf{1}} \pm \mathbf{E p}\right)\end{array}$ & $\begin{array}{c}\text { DAMM }(\%) \\
\operatorname{Média}^{\mathbf{1}}( \pm \mathbf{E p})\end{array}$ & $\begin{array}{c}\text { DAMO }(\%) \\
\left.\text { Média }^{\mathbf{1}} \pm \mathbf{E p}\right)\end{array}$ \\
\hline Milho integral & $86,28 \mathrm{~b}( \pm 0,78)$ & $20,16 \mathrm{~b}( \pm 4,34)$ & $87,19 \mathrm{~b}( \pm 0,74)$ \\
Milho degerminado & $67,82 \mathrm{c}( \pm 0,84)$ & $14,86 \mathrm{~b}( \pm 3,37)$ & $71,60 \mathrm{c}( \pm 0,70)$ \\
Sorgo integral & $86,43 \mathrm{~b}( \pm 1,04)$ & $27,48 \mathrm{ab}( \pm 5,29)$ & $87,48 \mathrm{~b}( \pm 0,98)$ \\
Quirera de arroz & $95,00 \mathrm{a}( \pm 0,72)$ & $41,08^{\mathrm{a}}( \pm 8,11)$ & $95,62 \mathrm{a}( \pm 0,64)$ \\
\hline CV $(\%)$ & 2,65 & 59,42 & 2,36 \\
\hline
\end{tabular}

${ }^{1}$ Valores em uma mesma coluna, seguidos de letras distintas, diferem pelo teste de $\mathrm{SNK}(\mathrm{P}<0,05)$. 
Silva et al. (1999), avaliando a digestibilidade do milho pré-cozido para cães, encontraram um coeficiente médio de digestibilidade da matéria seca de $94,30 \%$, valor acima do encontrado neste experimento para o milho integral. Segundo os autores, o valor encontrado ficou acima daqueles referenciados em outros trabalhos (FAHEY et al., 1990a, b; MUIR et al., 1996, citados por SILVA et al., 1999). Entretanto, naqueles trabalhos os valores foram obtidos com rações experimentais em que o nível de fibra bruta era maior que o encontrado no milho pré-cozido, o que, possivelmente, pode ser válido também para o milho utilizado neste experimento.

A quirera de arroz e o sorgo apresentaram os valores de DAMM semelhantes $(\mathrm{P}>0,05)$, embora a quirera tenha diferido $(\mathrm{P}<0,05)$ do milho integral e do milho degerminado, enquanto o sorgo foi semelhante a estes dois alimentos (P>0,05). O coeficiente de variação para este parâmetro foi alto $(59,42)$, o que pode ser devido a diferenças na absorção e excreção de minerais dos vários cereais testados.

Observou-se que a média da DAMO não diferiu $(\mathrm{P}>0,05)$ para os alimentos milho integral e sorgo, entretanto, estes dois alimentos apresentam diferença $(\mathrm{P}<0,05)$ quando comparados com o milho degerminado, sendo que este último apresentou o menor coeficiente de DAMO. Já a quirera de arroz apresentou os maiores valores, diferindo $(\mathrm{P}<0,05)$ de todos os tratamentos.

Murray \& Fahey (1999), avaliando a digestão ileal de várias farinhas de cereais para cães, observaram que o milho apresentou 85 e $89 \%$ de digestibilidade para a matéria seca e matéria orgânica, respectivamente, valores semelhantes aos encontrados neste experimento.

Na Tabela 2, encontram-se descritos os valores médios $(\%)$ dos coeficientes de digestibilidade aparente da proteína bruta (DAPB), da gordura por hidrólise ácida (DAGHA), da fibra bruta (DAFB) e do extrativo não nitrogenado (DAENN) dos tratamentos avaliados.

Para a DAPB, os alimentos milho integral, sorgo e milho degerminado não apresentaram diferença entre si (P> 0,05), apesar de o milho degerminado ter apresentado um valor maior de proteína bruta excretada. Porém, a quirera de arroz apresentou-se significativamente diferente dos demais alimentos, apresentando uma maior digestibilidade aparente da PB $(\mathrm{P}<0,05)$.

Twomey et al. (2002), em um experimento para avaliar o uso de sorgo e milho como alternativas para o arroz em alimentos para cães, encontraram digestibilidades aparentes da proteína de 87; 83 e $85 \%$ para o arroz, milho e sorgo, respectivamente, valores mais elevados que os encontrados neste experimento. Murray \& Fahey (1999) também encontraram valores de digestibilidade aparente da proteína bruta de 85,86 e $83 \%$ para o arroz, milho e sorgo, respectivamente, valores também maiores que os obtidos neste experimento. Como os resultados dos dois autores foram obtidos em dietas em que, além do cereal, outros ingredientes como a farinha de carne entravam em sua composição, possivelmente os altos valores foram resultantes de um valor de aditividade entre aminoácidos.

Não ocorreu diferença $(P>0,05)$ entre a DAGHA do milho integral e o sorgo . Porém, diferenças $(\mathrm{P}<0,05)$ foram encontradas entre a quirera de arroz e o milho degerminado e entre ambos e os demais alimentos avaliados. A quirera de arroz foi o alimento que apresentou maior DAGHA (\%).

Em experimento realizado por Murray \& Fahey (1999), foram encontrados valores de digestibilidade de gordura de 94, 93 e 94\% para o milho, sorgo e arroz, respectivamente, valores acima dos encontrados neste experimento, porém próximos para a DAGHA para a quirera de arroz. Do mesmo modo, os valores encontrados por Twomey et al. (2002), para a digestibilidade de gordura para o milho, sorgo e arroz foram elevados, de 97, 96 e 97\%, respectivamente. Vale ressaltar novamente que, os referidos autores trabalharam com dietas em que, além dos cereais testados, outros ingredientes, em particular a gordura de frango, faziam parte da composição básica; portanto, interações de aditividade entre os nutrientes podem ter ocorrido.

Encontrou-se um valor negativo na DAFB da quirera de arroz, o que se deve, possivelmente, à imprecisão e à falta de acurácia da técnica de fibra bruta, quando utilizada em alimentos com baixos teores de fibra. Isto pode ser confirmado pelos altos erros padrão da média (Ep) daqueles alimentos com baixa fibra (sorgo, milho integral e quirera) e pelo elevado coeficiente de variação $(329,0 \%)$. Por outro lado, a técnica parece ser adequada para o milho degerminado, que apresenta em torno de $20 \%$ de fibra bruta, o que pode ser confirmado pelo baixo erro padrão da média deste alimento $(1,96)$ quando comparado aos demais. Estes achados corroboram os resultados obtidos por Murray \& Fahey (1999), em um experimento com o objetivo de avaliar farinhas selecionadas com alto teor de amido como ingredientes em dietas caninas, os quais encontraram valores negativos de digestibilidade ileal da fibra dietética total do milho $(-5,0 \%)$.

Observou-se que as DAENN entre todos os alimentos foram diferentes entre si $(\mathrm{P}<0,05)$. A quirera de arroz apresentou o maior coeficiente de digestibilidade do extrativo não nitrogenado, diferindo $(\mathrm{P}<0,05)$ de todos os outros tratamentos. Por outro lado, o sorgo apresentou a segunda maior digestibilidade do extrativo não nitrogenado.

$\mathrm{O}$ alto valor de ENN encontrado neste experimento para a quirera de arroz foi semelhante ao de Twomey et al. 
(2002), que relataram um valor de $100 \%$ para a digestibilidade do amido do arroz. Da mesma forma, Murray \& Fahey (1999) encontraram uma digestiblidade do amido ileal e trato-gastrointestinal total também de $100 \%$ para o milho, sorgo e arroz.

Os valores médios (\%) dos coeficientes de digestibilidade da energia bruta (DAEB) e os valores de energia digestível (ED) em Kcal/kg, encontram-se expressos na Tabela 3. A quirera de arroz apresentou o maior coeficiente de DAEB $(\mathrm{P}<0,05)$, enquanto as DAEB do milho e sorgo não apresentaram diferenças $(\mathrm{P}>0,05)$ entre si, mostrando a similaridade do valor nutricional dos dois ingredientes. Já o milho degerminado apresentou o menor coeficiente de DAEB.

Twomey et al. (2002) encontraram valores para DAEB de 85,87 e $90 \%$ para o milho, sorgo e arroz, respectivamente, valores muito próximos dos encontrados neste experimento para o milho e sorgo e menores que o encontrado para quirera de arroz. No entanto, Silva et al. (1999) encontraram uma DAEB para o milho pré-cozido de 93\%, acima do encontrado neste experimento.

Quanto aos valores médios de ED de cada alimento, o milho integral e o sorgo não apresentaram diferença $(\mathrm{P}>0,05)$ entre si, contrariando o que normalmente se encontra para aves e suínos, para os quais o sorgo apresenta um valor energético em torno de $90 \%$ do valor energético do milho (ROSTAGNO et al., 2004).

A quirera de arroz apresentou os valores mais altos $(\mathrm{P}<0,05)$ de EDA, enquanto o milho degerminado, o valor mais baixo.

Silva Júnior (2004) encontrou valores de EDA de 3699,3629 e $3740 \mathrm{Kcal} / \mathrm{Kg}$ de matéria seca para dietas com milho, sorgo e quirera de arroz, respectivamente; entretanto, os valores encontrados pelo autor são referentes ao valor de EDA das dietas contendo apenas $60 \%$ do cereal a ser testado, o que pode justificar as variações nos resultados quando comparados aos encontrados neste experimento. O mesmo ocorreu com Silva et al. (1999), que encontraram valores de ED para o milho pré-cozido para cães, de 3523 $\mathrm{Kcal} / \mathrm{Kg}$ de matéria seca. Por outro lado, Murray \& Fahey (2002) encontraram valores de ED bastante elevados para o milho, sorgo e quirera de arroz, de 4137, 4235 e 4316 Kcal/ Kg de matéria seca, respectivamente.

TABELA 2 - Coeficientes (\%) de digestibilidade aparente da proteína bruta (DAPB), da gordura por hidrólise ácida (DAGHA), da fibra bruta (DAFB) e do extrativo não nitrogenado (DAENN), do milho integral, milho degerminado, sorgo integral e quirera de arroz em cães.

\begin{tabular}{|c|c|c|c|c|}
\hline Cereal & $\begin{array}{c}\text { DAPB (\%) } \\
\operatorname{Média}^{1}( \pm \text { Ep) }\end{array}$ & $\begin{array}{c}\text { DAGHA (\%) } \\
\operatorname{Média}^{1}( \pm \text { Ep) }\end{array}$ & $\begin{array}{c}\text { DAFB (\%) } \\
\operatorname{Média}^{1}( \pm \text { Ep) }\end{array}$ & $\begin{array}{c}\text { DAENN (\%) } \\
\text { Média }^{1}( \pm \text { Ep) }\end{array}$ \\
\hline Milho integral & $73,28 \mathrm{~b}( \pm 1,57)$ & $88,72 \mathrm{~b}( \pm 1,19)$ & $8,145( \pm 4,96)$ & $90,48 \mathrm{c}( \pm 0,63)$ \\
\hline Milho degerminado & $69,65 \mathrm{~b}( \pm 5,84)$ & $79,52 \mathrm{c}( \pm 1,18)$ & $9,77( \pm 1,96)$ & $76,82 \mathrm{~d}( \pm 0,52)$ \\
\hline Sorgo & $71,01 \mathrm{~b}( \pm 8,49)$ & $86,88 \mathrm{~b}( \pm 1,61)$ & $0,090( \pm 7,13)$ & $92,10 \mathrm{~b}( \pm 0,62)$ \\
\hline Quirera & $82,57^{\mathrm{a}}( \pm 2,20)$ & $92,66^{\mathrm{a}}( \pm 1,26)$ & $-63,051( \pm 8,12)$ & $98,09 \mathrm{a}( \pm 0,36)$ \\
\hline $\mathrm{CV}(\%)$ & 8,11 & 3,22 & 329 & 1,6 \\
\hline
\end{tabular}

${ }^{1}$ Valores em uma mesma coluna, seguidos de letras distintas, diferem pelo teste de $\mathrm{SNK}(\mathrm{P}<0,05)$.

TABELA 3 - Coeficientes (\%) de digestibilidade aparente da energia bruta (DAEB) e valores de enegia digestível aparente (EDA em kcal/kg) do milho integral, milho degerminado, sorgo integral e quirera de arroz, em cães.

\begin{tabular}{lcc}
\multicolumn{1}{c}{ Alimento } & $\begin{array}{c}\text { DAEB }(\%) \\
\mathbf{M e ́ d i a}^{1}( \pm \text { Ep) }\end{array}$ & $\begin{array}{c}\text { EDA }(\mathbf{K c a l} / \mathbf{k g}) \\
\left.\mathbf{M e ́ d i a}^{\mathbf{1}} \pm \mathbf{E p}\right)\end{array}$ \\
\hline Milho integral & $86,79 \mathrm{~b}( \pm 0,79)$ & $3796 \mathrm{~b}( \pm 34,5)$ \\
Milho degerminado & $72,84 \mathrm{c}( \pm 0,74)$ & $3046 \mathrm{c}( \pm 31,1)$ \\
Sorgo integral & $87,23 \mathrm{~b}( \pm 0,99)$ & $3872 \mathrm{~b}( \pm 43.7)$ \\
Quirera de arroz & $95,12 \mathrm{a}( \pm 0,71)$ & $4046 \mathrm{a}( \pm 30,2)$ \\
CV $(\%)$ & 2,51 & 2,5 \\
\hline
\end{tabular}

${ }^{1}$ Valores em uma mesma coluna, seguidos de letras distintas, diferem pelo teste de $\mathrm{SNK}(\mathrm{P}<0,05)$. 


\section{CONCLUSÕES}

A quirera de arroz apresentou maior coeficiente de digestibilidade dos princípios nutritivos dentre os alimentos avaliados.

O milho degerminado é um ingrediente de baixo valor nutricional quando comparado com o milho integral, sorgo e arroz, devendo ter sua utilização restrita somente a alimentos comerciais de baixa densidade energética, como aqueles para redução e controle de peso em cães.

O milho integral e o sorgo apresentaram valores de digestibilidades da matéria seca, matéria orgânica, proteína bruta, gordura em hidrólise ácida e energia bruta semelhantes.

\section{REFERÊNCIAS BILBIOGRÁFICAS}

AMERICAN FEED CONTROL OFFICIALS. Nutrient profiles for dogs and cats. Atlanta, 1994.

ASSOCIAÇÃO NACIONAL DOS FABRICANTES DE ALIMENTOS PARA ANIMAIS DE ESTIMAÇÃO ANFAL PET. Industry profile Pet Food 2005. Disponível em: 〈wWw. anfalpet.org.bir >. Acesso em: 20 mar. 2005.

ASSOCIATION OF OFFICAL ANALYTICAL CHEMISTS. Official methods of analysis of AOAC International. 16. ed. Arlington: AOAC International, 1995. v. 1.

BORGES, F. M. O. Utilização do sorgo em alimentos para animais de estimação. In: SIMPÓSIO SOBRE INGREDIENTES NA ALIMENTAÇÃO ANIMAL, 2., 2002, Uberlândia. Anais... Campinas: CBNA, 2002. p. 39-48.

BORGeS, F. M. O.; FERREIRA, W. M. Princípios nutritivos e exigências nutricionais de cães e gatos: parte I, energia, proteína, carboidratos e lipídeos. Lavras: UFLA/FAEPE, 2004. 108 p. Curso de Pós-Graduação "Lato Sensu" Especialização a Distância: Nutrição e Alimentação de Cães e Gatos.

BRASIL. Ministério da Agricultura, Pecuária e Abastecimento. Regulamento técnico sobre fixação de padrões de identidade e qualidade de alimentos para fins nutricionais especiais ou alimentos com fins nutricionais específicos destinados a cães e gatos. Instrução normativa/sarc $\mathrm{n}^{\circ} 9$, de 9 de julho de 2003. Diário Oficial da União, Brasília, Seção 1, de 14 de julho de 2003.
CARVALHO, A. Z. Processamento de alimentos para cães e gatos. In: SIMPÓSIO SOBRE NUTRIÇÃO DE ANIMAIS DE ESTIMAÇÃO, 2., 2002, Campinas. Anais... Campinas: CBNA, 2002. p. 194-202.

CORBIN, J. E. Pet food technology. [S.1.: s.n.], 2003. 514 p.

DUARTE, J. O. Cultivo do sorgo: mercado e comercialização. Brasília, DF: Embrapa Milho e Sorgo, 2000. Disponível em: $\langle\bar{h}$ ttp:///www.cnpms.embrapa.br/sorgo/importancia.htm Acesso em: 20 out. 2004.

FAO. El sorgo y el mijo: en la nutrición humana. Disponível em: $\langle$ http://Www.fao.org $>$. Acesso em: 2 jun. 2002.

FAPOJUWO, O. O.; MAGA, J.A.; JANSEN, G. R. Effect of extrusion cooking on in vitro protein digestibility of sorghum. Journal of Food Science, Chicago, v. 52, n. 1, p. 218-219, Jan./Feb. 1987.

FERREIRA, D. F. Análises estatísticas por meio do Sisvar para o Windows versão 4.0. In: REUNIÃO ANUAL DA REGIAO BRASILEIRA DA SOCIEDADE INTERNACIONAL DE BIOMETRIA, 45., 2000, São Carlos. Programas e Resumos... São Carlos: UFSCar, 2000. p. 255-258.

GONÇALVES, L. C.; BORGES, I. Alimentos e alimentação de gado de leite. Belo Horizonte: UFMG, 1997. 30 p. Apostila.

LEWIS, L. D.; MORRIS JUNIOR, M. L.; HAND, M. S. Small animal clinical nutrition III. Topeka: Mark Morris Institute, 1994.

MURRAY, S. M.; FAHEY JUNIOR, G. C. Evaluation of selected high-starch flours as ingredients in canine diets. Journal of Animal Science, Champaign, v. 77, n. 8, p. 21802186, Aug. 1999.

RIBAS, P. M. Cultivo do sorgo: importância econômica. Brasília, DF: Embrapa Milho e Sorgo, 2000. Disponível em: $\langle$ htttp://www.cnpms.embrapa.br/sorgo/importancia.htm> Acesso em: 22 nov. $200 \overline{4}$.

ROSTAGNO, H. S.; ALBINO, L. F. T.; TOLEDO, R. S. Utilização do sorgo nas rações de aves e suínos. Viçosa: UFV, 2004. Disponível em: <www.polinutri.com.brì. Acesso em: 10 jun. 2004.

SILVA, D. J.; QUEIROZ, A. C. Análise de alimentos: métodos químicos e biológicos. 3. ed. Viçosa: UFV, 2002. 235 p. 
SILVA, F. V.; VIANA, J. A.; DONZELE, J. L.; FONTE, D. O. Determinação da digestibilidade energia, proteína e matéria seca do milho pré-cozido em cães adultos. In: REUNIÃO ANUAL DA SOCIEDADE BRASILEIRA DE ZOOTECNIA, 36., 1999, Porto Alegre. Anais... Porto Alegre, 1999.

SILVA JÚNIOR, J. W. Digestibilidade de dietas com diferentes fontes de carboidratos e sua influência na glicemia e insulinemia em cães. 2004. 63 p. Dissertação (Mestrado em Zootecnia) - Universidade Federal de Lavras, Lavras, 2004.
TARDIN, A. C. Dietas com alta proteína e gordura na alimentação de cães e gatos. In: SIMPÓSIO SOBRE NUTRIÇÃO E ALIMENTOS PARA CÃES E GATOS, 2002, Lavras. Anais... Lavras: UFLA, 2002. p. 37-46.

TWONEY, L. N.; PETHICK, D. W.; ROWE, J. B.; CHOLT, M.; PLUSKE, J. R.; BROWN, W.; LAVISTE, M. C. The use of sorghum and corn as alternative to rice in dog foods. Journal of Nutrition, Bethesda, v. 132, n. 6, p. 1704-1705, June 2002 